\title{
Identification of the long non-coding RNA POU3F3 in plasma as a novel biomarker for diagnosis of esophageal squamous cell carcinoma
}

\author{
Yu-Suo Tong ${ }^{1 \dagger}$, Xiao-Wei Wang ${ }^{2 \dagger}$, Xi-Lei Zhou ${ }^{3 \dagger}$, Zi-Hao Liu ${ }^{1}$, Tong-Xin Yang ${ }^{1}$, Wei-Hong Shi ${ }^{1}$, Hai-Wei Xie ${ }^{1}$, Jin LV $^{1}$, \\ Qing-Quan $\mathrm{Wu}^{4}$ and Xiu-Feng Cao ${ }^{1^{*}}$
}

\begin{abstract}
Background: Recent studies have demonstrated that long non-coding RNAs (IncRNAs) were present in the blood of cancer patients and have shown great potential as powerful and non-invasive tumor markers. However, little is known about the value of IncRNAs in the diagnosis of esophageal squamous cell carcinoma (ESCC). We hypothesized that ESCC-related IncRNAs might be released into the circulation during tumor initiation and could be utilized to detect and monitor ESCC.

Methods: Ten IncRNAs (HOTAIR, AFAP1-AS1, POU3F3, HNF1A-AS1, 91H, PInCRNA1, SPRY4-IT1, ENST00000435885.1, XLOC_013104 and ENST00000547963.1) which previously found to be differently expressed in esophageal cancer were selected as candidate targets for subsequent circulating IncRNA assay. A four-stage exploratory study was conducted to test the hypothesis: (1) optimization of detected method to accurately and reproducibly measure ESCC-related IncRNAs in plasma and serum; (2) evaluation of the stability of circulating IncRNAs in human plasma or serum; (3) exploration the origin of ESCC-related IncRNAs in vitro and in vivo; (4) evaluation the diagnostic power of circulating IncRNAs for ESCC.

Results: ESCC-related InCRNAs were detectable and stable in plasma of cancer patients, and derived largely from ESCC tumor cells. Furthermore, plasma levels of POU3F3, HNFIA-AS1 and SPRY4-IT1 were significantly higher in ESCC patients compared with normal controls. By receiver operating characteristic curve (ROC) analysis, among the three IncRNAs investigated, plasma POU3F3 provided the highest diagnostic performance for detection of ESCC (the area under the ROC curve (AUC), 0.842; $p<0.001$; sensitivity, 72.8\%; specificity, 89.4\%). Moreover, use of POU3F3 and SCCA in combination could provide a more effective diagnosis performance (AUC, 0.926, $p<0.001$, sensitivity, 85.7\%; specificity, 81.4\%). Most importantly, this combination was effective to detect ESCC at an early stage (80.8\%).
\end{abstract}

Conclusions: Plasma POU3F3 could serve as a potential biomarker for diagnosis of ESCC, and the combination of POUSF3 and SCCA was more efficient for ESCC detection, in particular for early tumor screening.

Keywords: Esophageal cancer, Long non-coding RNAs, Plasma, Biomarker, Diagnosis

\section{Background}

Esophageal squamous cell carcinoma (ESCC) is one of the most fatal malignancies in humans, causing more than 400000 deaths per year [1]. Patients trend to present with dysphagia at an advanced stage, and the 5-year survival rate is less than $15 \%$ [2]. Current biomarkers such as

\footnotetext{
* Correspondence: cxf551101@sina.com

${ }^{\dagger}$ Equal contributors

'Department of Surgical Oncology, Nanjing Frist Hospital, Nanjing Medical

University, Nanjing, Jiangsu, China

Full list of author information is available at the end of the article
}

serum squamous cell carcinoma antigen (SCCA), carbohydrate antigen (CA) 19-9, and carcinoembryonic antigen (CEA) are the classic tumor markers commonly used in the management of patients with ESCC. However, these tumor markers, have limited utility in the early detection of ESCC due to lack of sufficiently high diagnostic sensitivity and specificity [3]. Although CYFRA 21-1 has been reported to have the higher sensitivity for diagnosing ESCC than the traditional tumor markers, the sensitivity is less than 10\% for early detection of ESCC [4]. Therefore, the significance of exploration of new biomarkers with

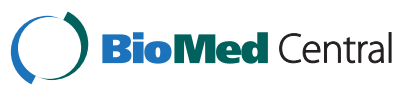

(c) 2015 Tong et al.; licensee BioMed Central. This is an Open Access article distributed under the terms of the Creative Commons Attribution License (http://creativecommons.org/licenses/by/4.0), which permits unrestricted use, distribution, and reproduction in any medium, provided the original work is properly credited. The Creative Commons Public Domain Dedication waiver (http://creativecommons.org/publicdomain/zero/1.0/) applies to the data made available in this article, unless otherwise stated. 
high sensitivity and specificity in early detection of ESCC should be emphasized.

Long non-coding RNAs (also known as lncRNAs), which are longer than 200 bases with lack of proteincoding capability, play critical roles in tumor initiation, progression and metastasis by modulating oncogenic and tumor-suppressing pathways [5,6]. Previous studies have proved that lncRNAs are frequently dysregulated expression in different kinds of tumors, including ESCC [7]. The aberrant expression of lncRNAs have been reported to serve as potential diagnostic or prognostic biomarkers for many human malignancies such as breast, lung, liver, and colon cancers [8-11]. Although these IncRNAs have shown great promise as a new kind of tumor markers, they cannot be used for clinical screening purposes because of difficulty in getting biopsies of tissue from patients suspected to be ESCC.

Circulating RNA in plasma or serum has been an emerging field for noninvasive diagnostic applications [12] More recently, MicroRNAs (miRNAs) have been detected in human peripheral blood, being remarkably stable in spite of the high amounts of endogenous ribonuclease in the blood of cancer patients [13]. Moreover, several clinical trials have been approved by the FDA to assess the value of serum miRNAs in cancer diagnosis (http://clinicaltrials. gov) [14]. At present, several lncRNAs have been characterized as potential tumor markers in human fluids. For example, MALAT1 was found to be significantly upregulated in plasma of prostate cancer patients, and could be used to discriminate cancer patients from healthy controls [6,15]. In gastric cancer patients, plasma AA174084 levels dropped markedly on day 15 after surgery compared with preoperative levels and were associated with invasion and lymphatic metastasis $[6,15]$. However, to our knowledge to date, no study has been performed regarding the circulating lncRNAs for early detection of ESCC patients.

In the present study, 10 lncRNAs (HOTAIR, AFAP1AS1, POU3F3, HNF1A-AS1, 91H, PlncRNA1, SPRY4-IT1, ENST00000435885.1, XLOC_013104 and ENST0000054 7963.1) that were previously reported with deregulated expression in esophageal cancer were selected as candidate diagnostic makers [16-23]. They were examined in tissues and plasma, and their potential use as tumor markers for ESCC detection were evaluated. We hypothesized that these ESCC-related IncRNAs might be released into the circulation during ESCC initiation and could be utilized to detect and monitor ESCC. To test the hypothesis, the following crucial questions need to be addressed: 1) the stability of circulating IncRNAs in plasma and serum, 2) the relationship between tumor tissue lncRNAs and circulating lncRNAs, 3) and the source of circulating lncRNAs (from cancer cells or from normal blood cells).

\section{Results}

Evaluation and screening of candidate endogenous control In order to evaluate and screen the optimal endogenous control for lncRNAs analysis of tissues and cells, the candidate reference genes (GAPDH, TBP, $\beta$-actin and HPRT1) were measured in 21-pair ESCC tumor tissues and adjacent normal tissues. The raw $\mathrm{Ct}$ values were provided in the supporting information (Additional file 1: Table S1). Finally, through four common algorithms (Normfinder, geNorm, BestKeeper, and the Comparative $\Delta \triangle$ Ct method) which were described elsewhere in details [24], GAPDH was identified as the most stable endogenous control for tissues $\operatorname{lncRNAs}$ analysis (Table 1).

However, for the early stage of circulating lncRNAs study, no consensus exists on the use of endogenous control for detection the lncRNAs in plasma. GAPDH, which was reported to be stably expressed in plasma and was selected as internal control in plasma by others before [15], was regarded as an ideal internal control for plasma assay. Therefore, GAPDH expression was measured in 270 plasma samples (147cases and 123controls). Results revealed that GAPDH level was stable in human plasma and was not affected by age, sex, and pathology (Additional file 2: Table S2).

\section{Selection and detection of ESCC-related IncRNAs}

On the basis of previous study, 10 lncRNAs (HOTAIR, AFAP1-AS1, POU3F3, HNF1A-AS1, PlncRNA1, SPRY4IT1, ENST00000435885.1, ENST00000547963.1, $91 \mathrm{H}$ and XLOC_013104) which have been reported to be differently expressed in esophageal cancer were selected in the present study. All the lncRNAs were then subjected to qPCR validation, which was performed in 48 pairs of ESCC tumor tissues and adjacent normal tissues. Among them, HOTAIR, AFAP1-AS1, POU3F3, HNF1A-AS1, PlncRNA1, SPRY4-IT1, ENSTO0000435885.1 and ENSTOO 000547963.1 were significantly higher in most of ESCC tumor tissues compared with paired adjacent normal tissues (Figure 1). However, expression of $91 \mathrm{H}$ and XLOC_013104 did not show any significantly different expression between the two groups and therefore were ruled out in the subsequent study (Figure 1).

Table 1 Results of using RefFinder to evaluate and screen the most stable endogenous control for tissues IncRNAs analysis

\begin{tabular}{lllll}
\hline Method & \multicolumn{2}{l}{$\begin{array}{l}\text { Ranking order } \\
\text { (better-good-average) }\end{array}$} \\
\hline$\triangle \triangle$ Ct method & GAPDH & HPRT1 & $\beta$-actin & TBP \\
BestKeeper & GAPDH & $\beta$-actin & HPRT1 & TBP \\
Normfinder & GAPDH & $\beta$-actin & HPRT1 & TBP \\
GeNorm & GAPDH & HPRT1 & $\beta$-actin & TBP \\
Recommended comprehensive ranking & GAPDH & HPRT1 & $\beta$-actin & TBP \\
\hline
\end{tabular}




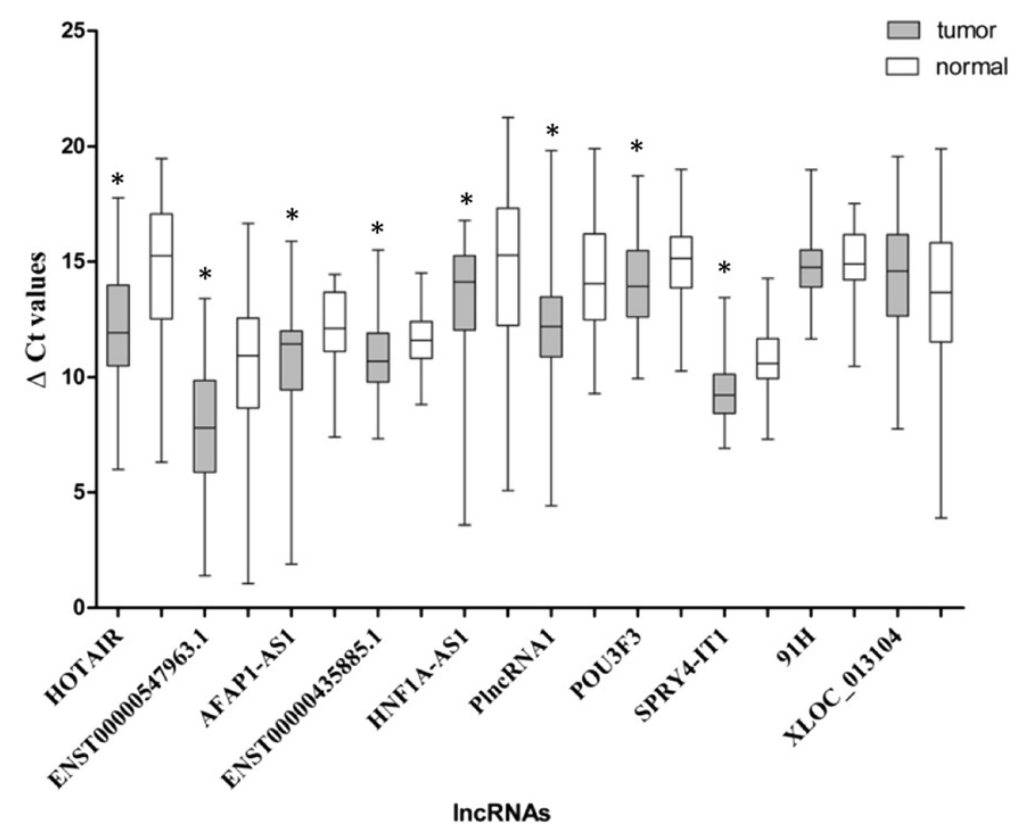

Figure 1 Validation of ESCC-related IncRNAs expression in ESCC tissues. $\triangle \mathrm{Ct}$ method was used to calculate IncRNA expression, which was normalized to $G A P D H$, and smaller $\triangle C$ t value indicated higher expression. Horizontal lines inside the box plots represent the median, boxes represent the interquartile range, and error bars represent 97.5 th and 2.5 th percentiles. ${ }^{*} P<0.05$.

The presence of ESCC-related IncRNAs in human plasma The detection of lncRNAs from plasma or serum with sufficient sensitivity is a prerequisite of developing circulating lncRNAs-based tumor markers. Therefore, optimization of extraction method was very important (detailed in Additional file 3: Text S1).

To explore whether these ESCC-related IncRNAs could reach the circulation at levels sufficient to be detectable, qPCR was then used to examine expression of selected 8 lncRNAs in 48 plasma samples (24 clinical samples and 24 normal controls). Of these lncRNAs, as shown in Figure $2 \mathrm{~A}-\mathrm{C}$, the levels of POU3F3 $(p<0.001)$, HNF1A-AS1 $(p<0.001)$ and SPRY4-IT1 $(p<0.001)$ were significantly higher in ESCC patients comparing with normal controls. Moreover, to make sure whether these IncRNAs were present in plasma, the qPCR products were further validated by using traditional Sanger-based method. As expected, their sequences were identical to those derived from POU3F3, HNF1A-AS1 and SPRY4IT1 (Additional file 4: Figure S1). The results indicated that ESCC-related lncRNAs could enter into the circulation and their differentiate expression in plasma could be used as diagnostic markers for ESCC. However, PlncRNA1, HOTAIR and ENST00000547963.1 had a detection rate of less than $60 \%$ in both ESCC plasma samples and normal controls, and therefore were excluded. In addition, ENST00000435885 $(p=0.386)$ and AFAP1AS1 $(p=0.232)$ were also excluded because there were no significant differences in their expressions between the two groups (Additional file 5: Figure S2).

\section{Stability of ESCC-related IncRNAs in human plasma}

To determine the stability of lncRNAs in plasma, given that this is a crucial prerequisite for utility as tumor markers, plasma samples were left under harsh conditions including incubation at room temperature for 0,6 , and $24 \mathrm{~h}$, repeated freeze-thaw cycles, or low/high $\mathrm{pH}$, respectively. A total of 12 ESCC plasma samples were assessed, and they were divided into three portions. At room temperature, the levels of POU3F3, HNF1A-AS1 and SPRY4-IT1 were not significantly altered from $0 \mathrm{~h}$ to $6 \mathrm{~h}$, but then slightly decreased at $24 \mathrm{~h}$ when compared with $6 \mathrm{~h}$ (Figure 3A). The stability of plasma IncRNAs was treated with strong acid, strong base, or 10 multiple freeze-thaw cycles, respectively, for further validation. As shown in Figure $3 \mathrm{~B}$ and $\mathrm{C}$, lncRNAs in treated plasma remained stable compared to plasma not treated Given that circulating lncRNA has been thought to be unstable, because of the existence of the endogenous RNase in blood. Three additional ESCC plasma samples were incubated with RNase A for $3 \mathrm{~h}$ at room temperature to determine whether lncRNAs could be degradated. Results indicated that RNase A had hardly any effect on plasma level of POU3F3, HNF1A-AS1 and SPRY4-IT1 (Figure 3D). 

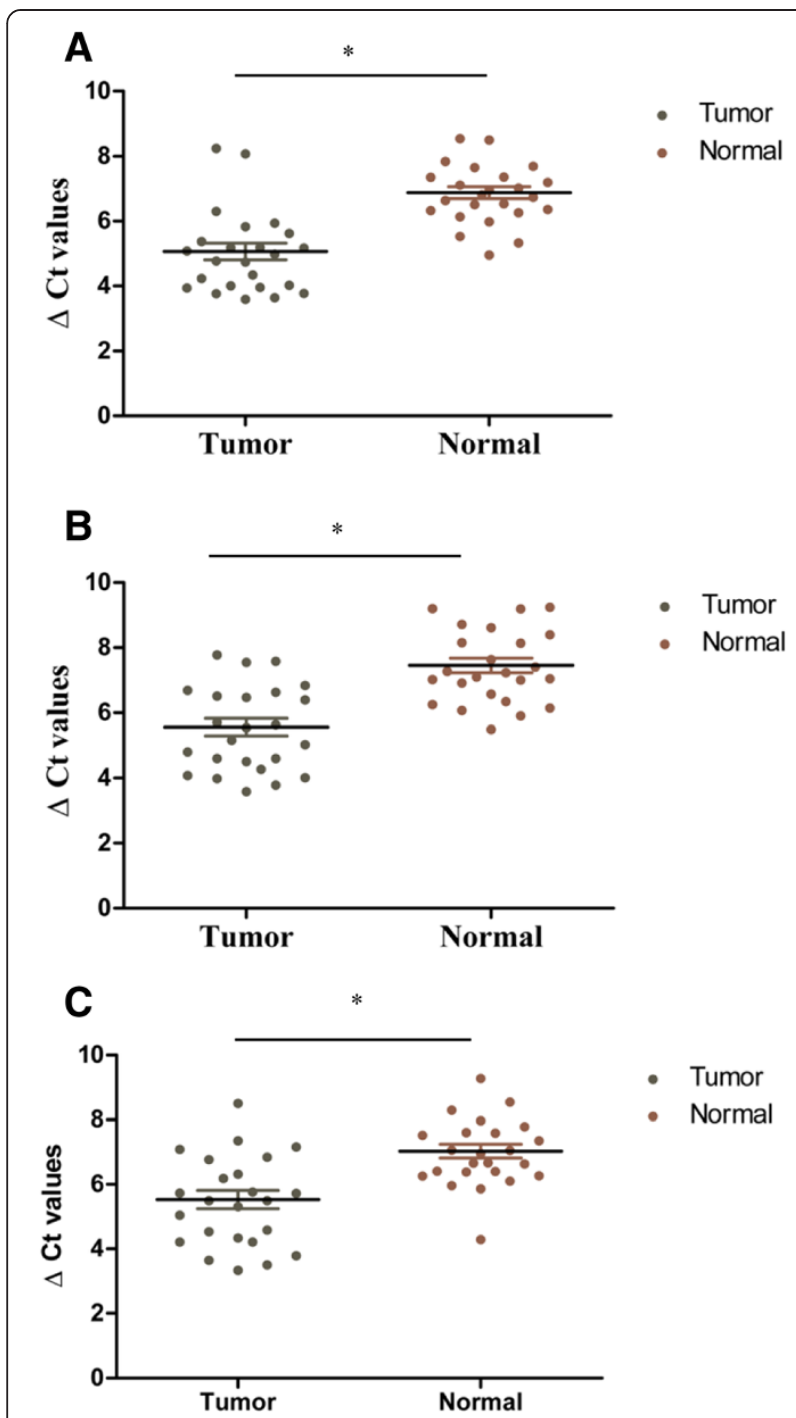

Figure 2 ESCC-related IncRNAs were detectable in plasma of tumor patients and normal control. (A-C) Plasma levels of POU3F3 (A), HNFIA-AS1 (B), and SPRY4-IT1 (C) were measured in 24 clinical samples and 24 cancer free controls. Horizontal bars indicate median and interquartile range. Circulating IncRNAs expressions were calculated using $\Delta \mathrm{Ct}$ method. Statistical differences were analyzed using Mann-Whitney test. ${ }^{*} p<0.001$.

\section{Comparison of ESCC-related IncRNAs between plasma and serum}

To test whether there was a relationship between plasma and serum lncRNAs level, POU3F3, HNF1A-AS1 and SPRY4-IT1 were measured in EDTA-plasma samples and clotted blood from the same individuals at the same blood draw. As shown in Figure 4, measurements obtained from plasma and serum were strongly correlated for POU $3 F 3$ $(r=0.833$, mean differences $=-0.71 \pm 0.75$, Figure 4A), HNF1A-AS1 $(r=0.771$, mean differences $=-0.55 \pm 1.12$,
Figure 4B) and SPRY4-IT1 $(r=0.724$, mean differences = $-1.07 \pm 0.95$, Figure $4 \mathrm{C}$ ), respectively. The results suggested that serum and plasma samples were both acceptable for evaluation of lncRNAs as blood-based tumor markers.

\section{Origin of ESCC-related IncRNAs in plasma}

To further test the hypothesis that plasma lncRNAs were primarily released or leaked from the tumor cells. Five independent experiments were carried out to determine the source of ESCC-related lncRNAs in plasma.

In the first experiment, qPCR was used to measure the POU3F3, HNF1A-AS1 and SPRY4-IT1 expression in different five esophageal cell lines (including four ESCC cells: KYSE30, KYSE70, KYSE450, and Eca 109, and one normal human esophageal epithelial cell line: HET-1A), and each cell culture medium which was incubated for 1,2 , and $3 \mathrm{~d}$ (Figure $5 \mathrm{~A}$ and $\mathrm{B}$ ). Data presented in Figure $5 \mathrm{~B}$ indicated that ESCC-related lncRNAs could enter into the cell culture medium at a detectable level and were steadily increased among the three incubation time points in the all four ESCC cell lines; however, no significant changes were observed in normal esophageal epithelial cell culture medium.

In the second experiment, a mouse ESCC xenograft model system was established to further investigate whether ESCC-related IncRNAs could enter the circulation at a measurable level. Blood samples were collected 4 weeks after implanting the KYSE30 cells or PBS, and the blood processing and RNA isolation were the same as those described for human plasma. Then the qPCR results demonstrated that the presence of tumor was the major contributor to plasma lncRNAs (Figure 5C).

In the third experiment, qPCR was used to measure the ESCC-related lncRNAs expression in 24 ESCC tumor tissues and paired plasma samples, and then correlation of the levels of ESCC-related IncRNAs between the two groups was analyzed. As shown in Figure 5D, a moderate significant correlation was observed for POU3F3 ( $r=$ 0.497, $p=0.001), H N F 1 A-A S 1 \quad(r=0.538, p<0.001)$, and SPRY4-IT1 ( $(r=0.633, p<0.001)$, respectively, which was consistent with our previous hypothesis.

Since circulating lncRNAs were primarily released or leaked from tumor cells, they would presumably revert to normal after the tumor has been resected. To test this hypothesis, the fourth experiment was carried out to investigate the differences in ESCC-related lncRNAs in plasma before and 14d after surgery. As expected, plasma levels of POU3F3 $(p<0.001$, Wilcoxon test) HNF1A-AS1 $(p=$ 0.002 , Wilcoxon test) and SPRY4-IT1 ( $p=0.001$, Wilcoxon test) were markedly declined $14 \mathrm{~d}$ after surgical treatment compared with before surgery (Figure 5E).

In addition, previous studies reported that some circulating RNAs could derive from the blood cells [25]. Therefore, the fifth experiment with delayed blood 


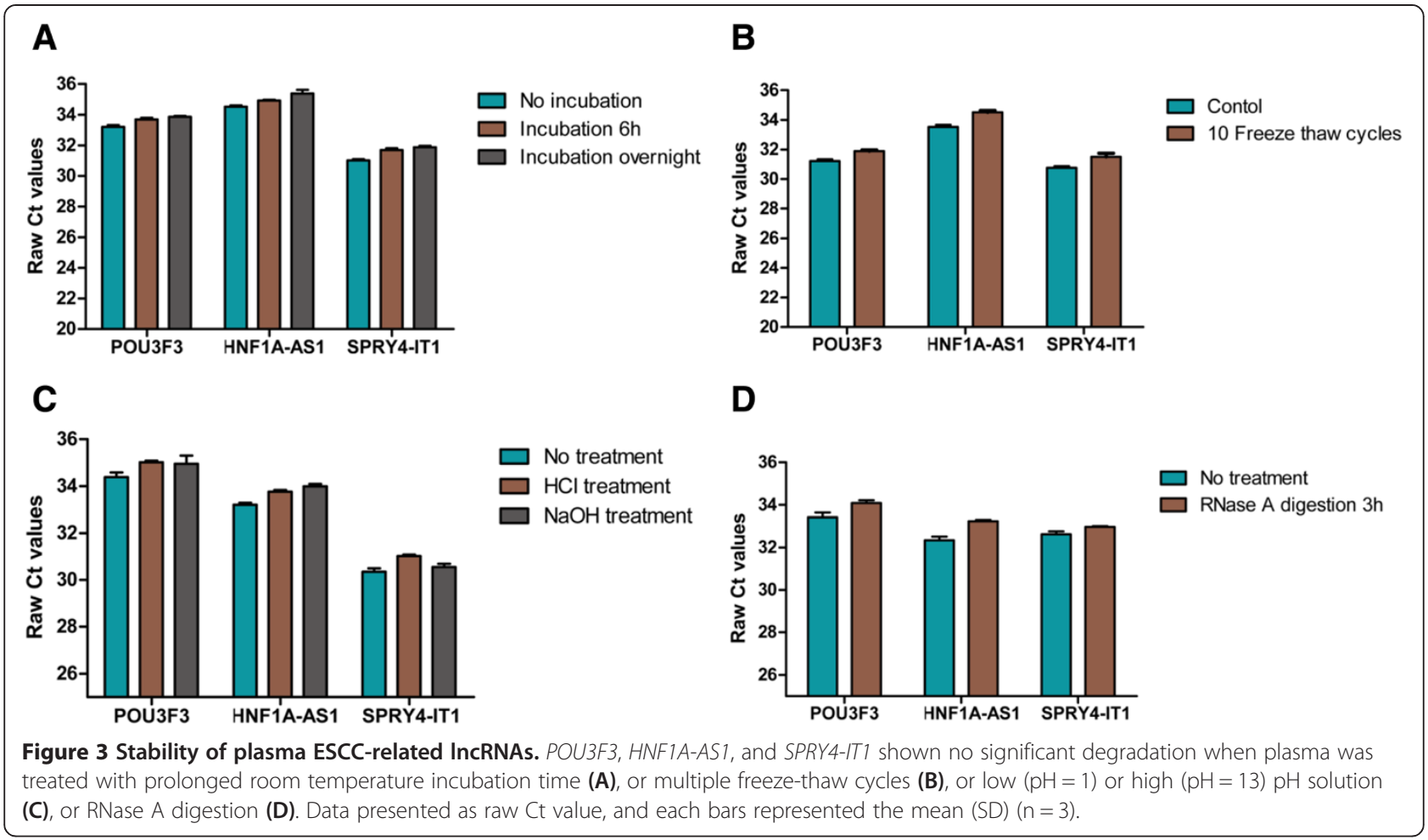

centrifugation after venesection was performed to further clarify the origin of circulating ESCC-related IncRNAs. A total of 12 EDTA-blood samples collected from healthy participants were used in this part of study. Four blood samples were incubated at room temperature for $0,6,12$, and $24 \mathrm{~h}$, and the second 4 blood samples were left at $4^{\circ} \mathrm{C}$ for $0,6,12$, and $24 \mathrm{~h}$. The last 4 blood samples were treated as the same as the first part, but the collected plasma was filtered through a $0.22 \mu \mathrm{m}$ filter. After the treatment, plasma was then collected for RNA isolation. The results showed that, at room temperature, POU3F3, HNF1A-AS1 and SPRY4-IT1 expression in the unfiltered plasma was slightly increased at $6 \mathrm{~h}$ compared to $0 \mathrm{~h}$, but then significantly declined at $24 \mathrm{~h}$ compared to $6 \mathrm{~h}$ (Figure 5F). However, no significant differences were observed when the EDTAblood was left at $4^{\circ} \mathrm{C}$ or for the filtered plasma (Additional file 6: Figure S3).

\section{Correlation between plasma IncRNAs and clinicopathological characteristics}

To further determine whether the three lncRNAs levels in ESCC plasma were associated with specific clinicopathologic parameters, such as gender, tumor size, histologic grade, smoking status, alcohol consumption, TNM stage, and clinical stage. POU3F3, HNF1A-AS1 and SPRY4IT1 expression levels were measured in all 147 ESCC patients; however, there was no significant association between plasma lncRNAs and clinicopathological parameters (Additional file 7: Table S3).

\section{Evaluation of IncRNAs in plasma as novel tumor markers for ESCC}

To investigate the characteristics of the three ESCCrelated lncRNAs as potential tumor markers of ESCC, Receiver operating characteristics (ROC) curves and the area under the ROC curves (AUC) were performed on data from all subjects, including 147 ESCC patients and 123 healthy donors. The ROC curves illustrated strong separation between the ESCC patients and control group, with an AUC of 0.842 (95\% CI: $0.794-0.890 ; p<0.001)$ for POU3F3, 0.781 (95\% CI: $0.727-0.835: p<0.001$ ) for HNF1A-AS1, and 0.800 (95\% CI: $0.748-0.853: p<0.001$ ) for SPRY4-IT1, respectively, compared with classic tumor marker SCCA $(\mathrm{ng} / \mathrm{ml})$ with an AUC of 0.784 (95\% CI: $0.727-0.841 ; p<0.001$ ) (Figure 6). Moreover, plasma level of POU $3 F 3$ could discriminate ESCC from normal controls with $72.8 \%$ sensitivity and $89.4 \%$ specificity, although the levels of HNF1A-AS1 and SPRY4-IT1 in plasma were less sensitive (32.7\% and 48.2\%) for ESCC detection. Therefore, of the three lncRNAs in this analysis, $P O U 3 F 3$ provided the highest diagnostic power for the detection of ESCC, suggesting that plasma POU3F3 could serve as a promising tumor marker for ESCC diagnosis. 

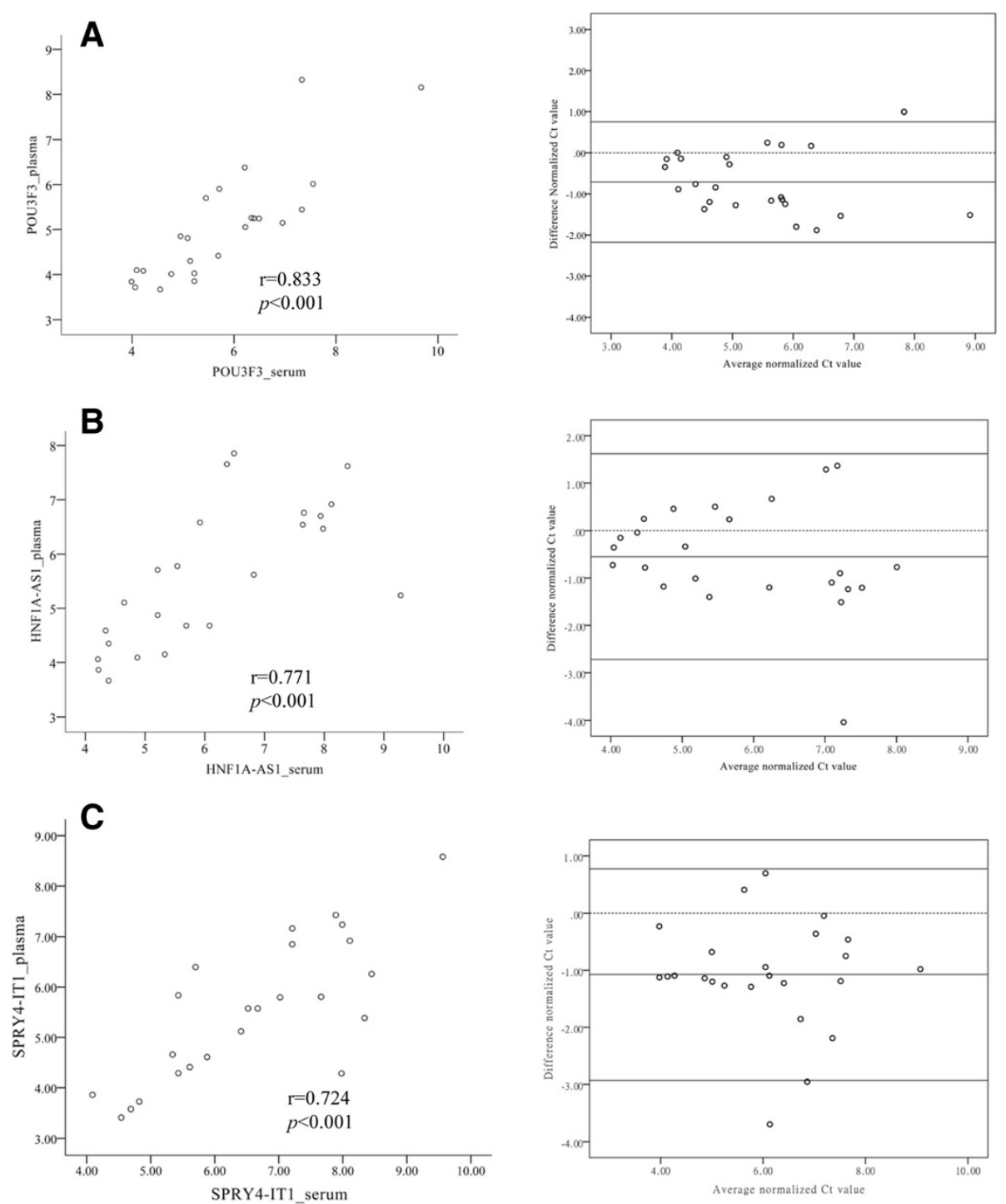

Figure 4 Correlation of ESCC-related IncRNAs expression between plasma and serum. Left panel, linear correlation plot of POU3F3 (A), HNF1A-AS1 (B) and SPRY4-IT1 (C) level from plasma (y-axis) versus from serum ( $x$-axis). There was a high correlation comparing the indicated IncRNAs levels between plasma and serum. Spearman's rank analysis was used to identify the correlation of IncRNAs levels between plasma and serum. Right panel, Bland-Altman plot of the difference between plasma and serum ESCC-related IncRNAs level (y-axis) versus their average ( $x$-axis). Horizontal solid lines in the middle represent the mean difference. Upper and lower solid lines represent the limits of agreement (95\% confidence intervals).

\section{Combination of POU3F3 and SCCA for ESCC diagnosis}

There is increasing evidence showing that combination several tumor markers could improve diagnostic accuracy. In this study, we determined whether the combination of POU $3 F 3$ and SCCA would provide a more effective diagnosis performance for detection of ESCC. As shown in Figure 7, by binary logistic regression, combination of POU $3 F 3$ and SCCA yielded an AUC of 0.926 (95\% CI: $0.896-0.955 ; p<0.001$ ), which was significantly improved compared with SCCA $(\mathrm{AUC}=0.784$ ) or lncRNA POU3F3 (AUC =0.842) alone. The sensitivity, specificity, accuracy of SCCA, POU3F3, and the combination (SCCA + POU3F3) for distinguishing ESCC from healthy controls were summarized in Table 2.

\section{Tumor stage and performance of the combination of POU3F3 and SCCA}

The key aim of this work was to diagnose ESCC patients at as early stage as possible at the time cancer therapy could be more likely successful. Therefore, the diagnostic positivity rate between different clinical stages was then investigated. As shown in Table 3, in stage I, the 


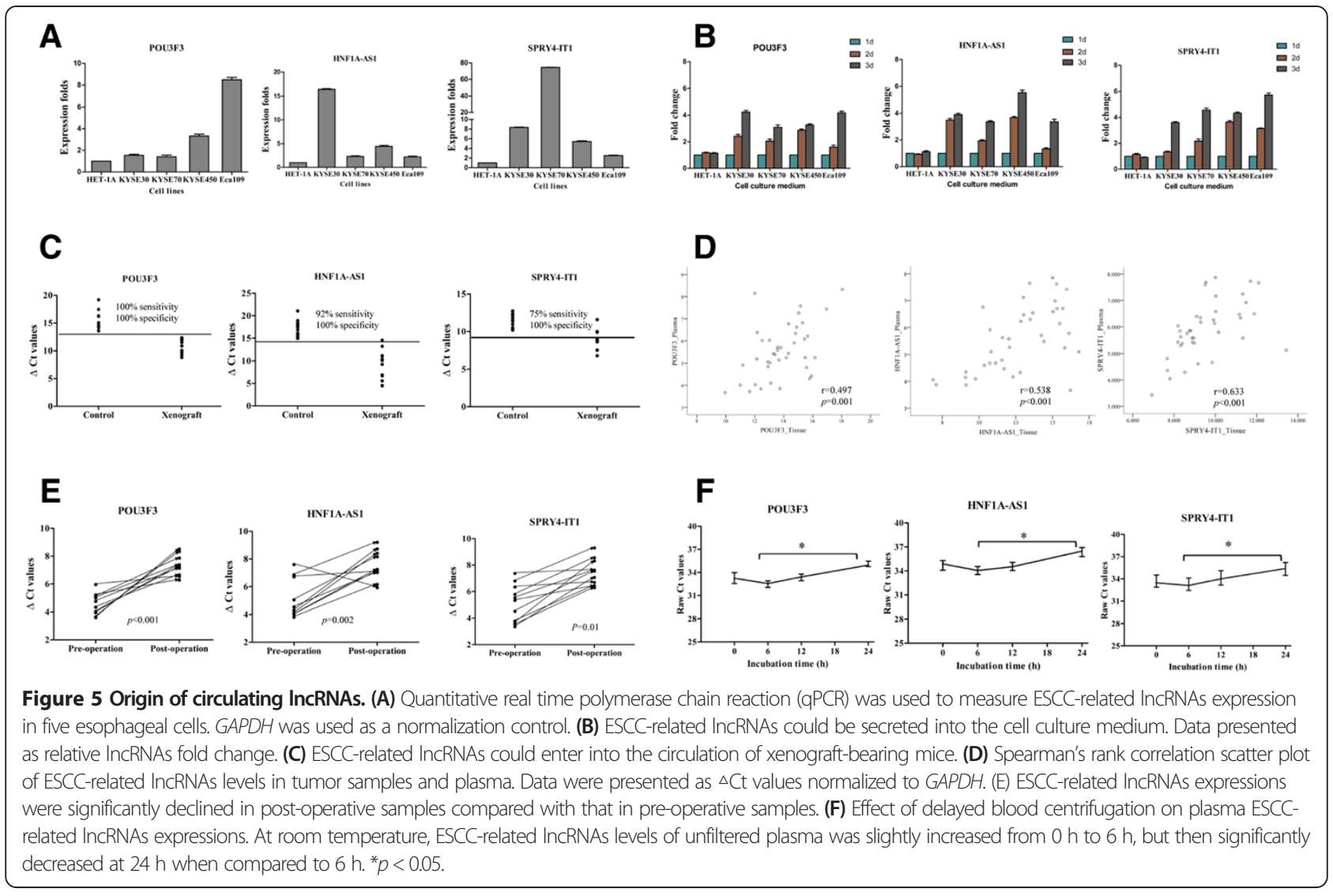

diagnostic positivity rate for SCCA, POU $3 F 3$, and both in combination was $26 \%, 69.2 \%$, and $80.8 \%$, respectively.

\section{Discussion}

Recently, it has been demonstrated that the cell-free nucleic acids are detectable in plasma and serum of cancer patients and therefore may be utilized as a tool for cancer diagnosis [26]. Although numerous studies have focused on miRNAs as potential tumor markers for cancer diagnosis and prognosis prediction, the diagnostic utility of plasma lncRNAs in ESCC has never been studied.

In the present study, the initial ESCC-related lncRNAs screening was performed based on different expression profiling between ESCC tumor samples and matched normal samples that have been demonstrated in previous studies. All lncRNAs of interest were then subjected to $\mathrm{qPCR}$ validation. Eight lncRNAs were identified and then further measured their expression levels in plasma from ESCC patients and healthy subjects. The results demonstrated that the levels of POU3F3, HNF1A-AS1 and SPRY4-IT1 were significantly higher in plasma from ESCC patients compared with normal controls, providing strong evidence that ESCC-related lncRNAs could be released into the circulation and that their different expression profiles in plasma could be used as diagnostic markers for ESCC. Among the three lncRNAs, POU3F3 provided the highest diagnostic power for detection of ESCC (AUC $=0.842$; sensitivity, $72.8 \%$; and specificity, $89.4 \%$ ), suggesting that plasma POU $3 F 3$ could serve as a promising tumor marker for ESCC detection. Furthermore, use of POU $3 F 3$ and SCCA in combination could provide a more powerful differential diagnosis between ESCC patients and healthy controls than use of POU3F3 or SCCA alone. Therefore, both in combination could be used as a diagnostic tool for screening apparently healthy individuals. Most importantly, the results indicated that plasma POU $3 F 3$ was more effective than SCCA for early detection of ESCC (69.2\% vs $26 \%)$, and that the positivity rate of both in combination was significantly improved compared with SCCA or POU $3 F 3$ alone. In addition, we also proved the mirVana PARIS Kit (Ambion 1556, USA) approach as the most effective RNA extraction method, and both plasma and serum would be acceptable for evaluation of lncRNAs as bloodbased tumor markers. This is the first time to systematically characterize circulating lncRNAs in plasma as diagnostic markers for ESCC.

Recently, many tumor markers such as SCCA, CEA, CA19-9, MMP-9, IL-6, CYFRA 21-1, DKK-1, M-CSF, MiR-18a, MiR-1246 and many other genes were evaluated for ESCC diagnosis [3,27-30]. However, there was no sufficient sensitivity and specificity for these biomarkers, even 


\section{A}

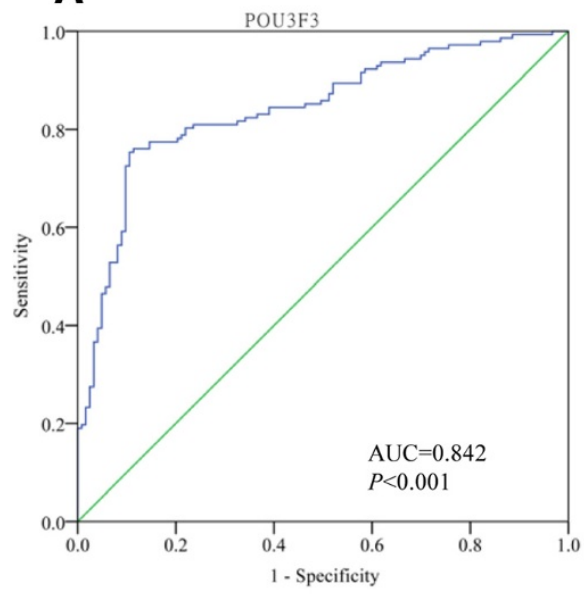

C

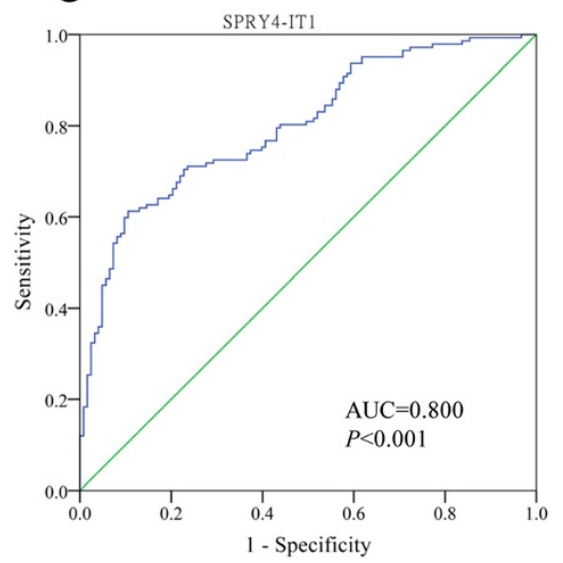

B

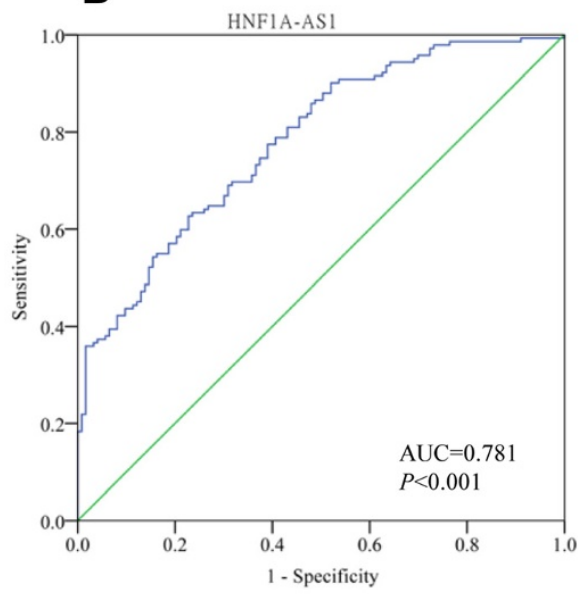

D

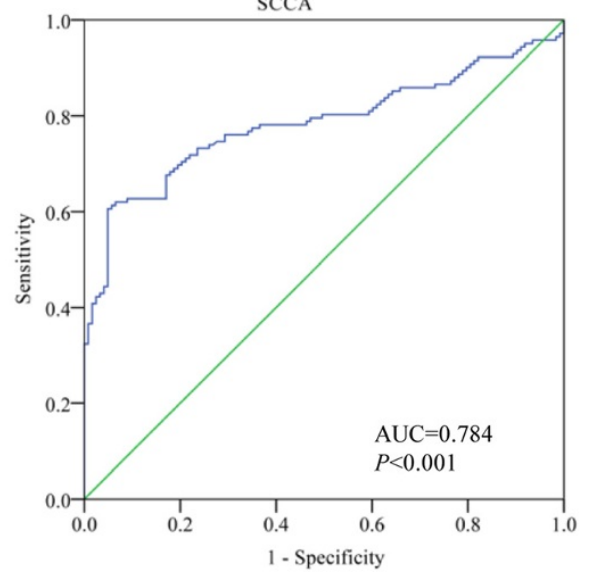

Figure 6 Evaluation of plasma IncRNAs for detection of ESCC. Receiver operating characteristics (ROC) curves were drawn with the data of plasma IncRNAs from 147 patients with ESCC and 123 healthy controls. (A-D) ROC-AUC for detecting ESCC from healthy controls (POU3F3, 0.842, $p<0.001 ;$ HNFTA-AS1, 0.781, $p<0.001 ;$ SPRY4-IT1, 0.800, $p<0.001 ;$ SCCA, $0.784, p<0.001)$.

for the most commonly used biomarkers such as serum CEA and SCCA. Mealy K reported that the individual sensitivities of CEA and SCCA for the diagnosis of ESCC were about $28 \%$ and $32 \%$, respectively [28]. Yamamoto $\mathrm{K}$ study demonstrated that the sensitivity of CYFRA 21-1 was only $47.9 \%$, although the specificity was $100 \%$ [31]. MMP-9 has been shown to have higher diagnostic sensitivity of ESCC compared to SCCA, but its diagnostic performance was poorer [31]. Serum MiR-1246 improved the discriminatory power, but sensitivity and specificity were lower $[30,32]$. This study was sought to find novel markers that could improve early detection of ESCC. Our results demonstrated that plasma IncRNA POU $3 F 3$ was a promising tumor marker, which effectively supplemented the serum SCCA for ESCC detection.

In the past several years, $\mathrm{qPCR}$ has been considered to be a reliable method for quantitative gene expression due to its accuracy, sensitivity, specificity, reproducibility and robustness [33]. However, to produce accurate results in $\mathrm{qPCR}$ assays the use of robust normalization strategy is important [34]. Generally, the use of reference gene as endogenous controls is the most commonly method for normalizing qPCR gene expression data. Currently, several mathematical algorithms which are specifically developed for reference gene evaluation and selection deliver suitable reference genes with the lowest variation and with high stability across the biological samples. The four commonly used approaches are: (1) NormFinder algorithm which is a statistical model that estimates the overall variation of gene expression for each candidate reference gene and delivers a stability value. (2) GeNorm. (3) BestKeeper, a Microsof Excel-based tool, uses pair-wise correlation and (4) the comparative delta Ct [35]. Therefore, in this study we paid special attention on reference genes selection. All candidate reference genes for ESCC tissue lncRNAs normalization were chosen based on their stably expressed in different human tissues or were once used in ESCC qPCR study. Finally through 


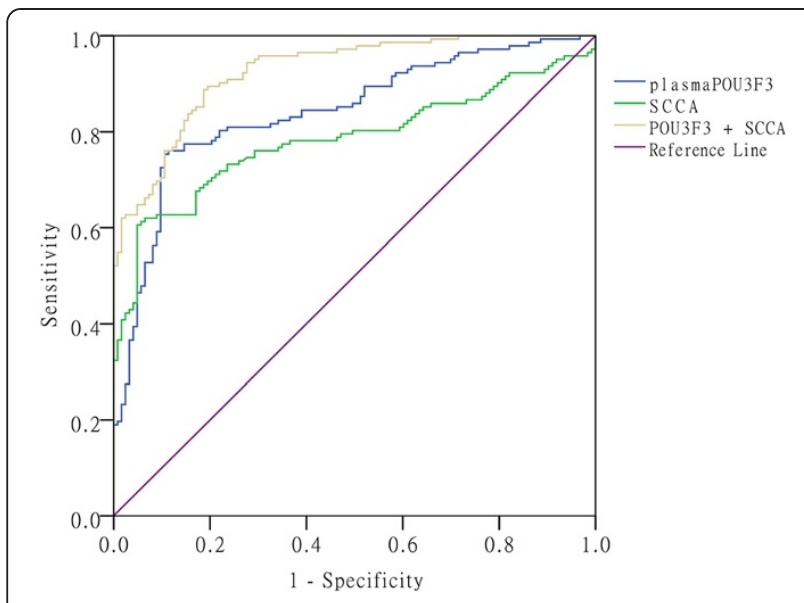

Figure 7 ROC corves to compare the diagnostic performance of SCCA, POU3F3, and a combination of SCCA and POU3F3, to discriminate ESCC from normal controls. The combination of SCCA and POU3F3 provided a more powerful differential diagnosis compared with SCCA and POU3F3 alone (SCCA+ POU3F3, 0.926, $p<$ 0.001; POU3F3, 0.842, $p<0.001$; SCCA, 0.784, $p<0.001$ ).

mathematical algorithms, GAPDH was selected for normalization of tissue lncRNAs measurement because of its best reference performance (Table 1). This was in agreement with $\mathrm{Li}$ W [18], using GAPDH normalization lncRNA POU $3 F 3$ expression in tissue samples of ESCC patients. As there was no established endogenous control for detection of plasma or serum lncRNAs, GAPDH was selected as a potential reference gene. And we observed that plasma GAPDH expression level was stable between the ESCC group and normal control group and was not affected by age, sex, and pathology. However, in the previous study by $\mathrm{Ng}$ EK et al. [36]. GAPDH seemed to be no feasible reference gene because of its expression level in HCC patients was significantly higher than those in health individuals. One possible explanation was that different diseases and selected primer pair was not the best choice for measuring gene expression could influence the expression of GAPDH.

Circulating lncRNAs were thought to be unstable because of the high level of RNase activity in plasma, and in cancer patients, increased plasma RNase has been detected [12]. In the present study, we confirmed that circulating lncRNAs were remarkably stable even when treated directly with RNase A digestion. These findings were consistent with those in patients with prostate cancer [6]. However, the precise mechanism used to explain why circulating lncRNAs are resistant to endogenous RNase digestion remains largely unknown. One explanation is that they are packaged in some kinds of microparticles, such as exosomes, microvesicles, apoptotic bodies, and apoptotic microparticles [14,37]. Our results of the blood-processing assay support this explanation. Recently, it has been hypothesized that circulating RNAs could be modified in certain ways, including methylation, adenylation, and uridylation which make them resistant to RNase digestion [38]. Another possible explanation is that lncRNAs often forms secondary structures, and relatively more stable, which could facilitate their detection as free nucleic acids in body fluids such as blood and urine [39]. The mechanism of resistance of circulating lncRNAs to RNase deserves further study. In the present study, we also demonstrated that plasma lncRNAs were resistant to multiple freeze-thaw cycles, strong acid and base treatment. However, when plasma or unprocessed blood was subjected to extended room temperature incubation, the concentrations of lncRNAs were even more variable. Such artifactual fluctuations in lncRNAs concentrations may be attributable to two factors: the secreted lncRNA from necrotic and/ or apoptotic blood cells; the stability of original and the newly secreted lncRNA [12]. Taking the unprocessed EDTA-blood for instance (Figure 5F); an initial increase in lncRNAs concentrations at $6 \mathrm{~h}$ may be the result of the newly released lncRNAs from blood cells. After that, the lncRNA concentrations started to decline which may be attributable to the degradation of the newly secreted lncRNAs. Based on the above results, we recommend that the unprocessed EDTA-blood should be stored at $4^{\circ}$ C.

The release of nucleic acids into the blood is thought to be associated with apoptosis and necrosis tumor cells from the tumor microenvironments and is also the results of secretion $[40,41]$. In the previous study of circulating lncRNA LIPCAR in heart failure patients from Kumarswamy and his colleges, who suggested that a good proportion of mitochondrial lncRNAs detected in circulation might come from the heart [42]. On the contrary, Prichard et al. provided the pioneering evidence that blood cells were the major contributor to the

Table 2 Performance of SCCA, POU3F3, and both SCCA and POU3F3 in the differential diagnosis ESCC from healthy participants

\begin{tabular}{lllllcccc}
\hline & Sensitivity & Specificity & Accuracy & Youden index & True positive & True negative & False-positive & False-negative \\
\hline SCCA & $59.2 \%$ & $93.5 \%$ & $74.8 \%$ & $52.7 \%$ & 87 & 115 & 8 & 60 \\
POU3F3 & $72.8 \%$ & $89.4 \%$ & $80.3 \%$ & $62.2 \%$ & 107 & 110 & 13 & 40 \\
SCCA + POU3F3 & $85.7 \%$ & $81.4 \%$ & $83.7 \%$ & $67.1 \%$ & 126 & 100 & 23 & 21 \\
\hline
\end{tabular}

Abbreviations: SCCA squamous cell carcinoma antigen. 
Table 3 Performance of SCCA, POU3F3 and both SCCA and POU3F3 in the detection of different clinical stage ESCC

\begin{tabular}{|c|c|c|c|c|c|c|}
\hline & \multicolumn{5}{|c|}{ Clinical stage } & \multirow{2}{*}{$\begin{array}{l}P \text { (Pearson } \\
\text { Chi-square) }\end{array}$} \\
\hline & 1 & II & III & IV & Total & \\
\hline SCCA & $26 \%(7 / 26)$ & $35.9 \%(14 / 39)$ & $76.4 \%(39 / 51)$ & $87.1 \%(27 / 31)$ & $59.2 \%(87 / 147)$ & 0.000 \\
\hline POU3F3 & $69.2 \%(18 / 26)$ & $66.6 \%(26 / 39)$ & $78.4 \%(40 / 51)$ & $74.2 \%(23 / 31)$ & $72.8 \%(107 / 147)$ & 0.455 \\
\hline $\mathrm{SCCA}+$ POU3F3 & $80.8 \%(21 / 26)$ & $76.9 \%(30 / 39)$ & $90.2 \%(46 / 51)$ & $93.5 \%(29 / 31)$ & $85.7 \%(126 / 147)$ & 0.147 \\
\hline$P$ (combination vs. SCCA) & 0.000 & 0.001 & 0.109 & 0.671 & 0.000 & \\
\hline
\end{tabular}

Abbreviations: SCCA squamous cell carcinoma antigen, statistic analysis, Pearson Chi-Square or Fisher's Exact Test.

circulating miRNAs and that perturbations in blood cell counts and hemolysis could alter plasma miRNAs levels by up to 50 -fold [25]. Another possible origin may be that the circulating miRNAs of cancer patients were not just a result of cancer but may actively contribute to cancer defense, because the population of circulating miRNAs correlated tightly with the immune response [40]. Currently, there were three major hypotheses for circulating miRNAs to enter into the circulation: energyfree passive leakage of cellular miRNAs into circulation; active and selective secretion of miRNAs in response to various stimuli as microvesicle-free miRNAs; and active secretion via cell-derived microvesicles [38]. These theories could also be utilized to explain the origin of circulating lncRNAs. In this study, we found that ESCC-related lncRNAs could enter into the cell culture medium at a measurable level. Furthermore, ESCC-related lncRNAs were derived from tumor cells as evidenced with the xenograft assay, the relationship of ESCC-related lncRNAs levels between the tumor samples and plasma matched for the same individuals, and the changes of plasma ESCC-related lncRNAs concentrations between pre-Op and post-Op. However, the delayed blood processing assay suggested that the circulating lncRNAs could also be released from blood cells although their contribution was minor. Therefore, to avoid the origin of lncRNAs from blood cells, the unprocessed blood should be stored at $4^{\circ} \mathrm{C}$ and further processed as soon as possible. In addition, the stable levels of the three lncRNAs in the filtered plasma could be used to explain why increased plasma lncRNAs detected in unfiltered blood samples were largely from microparticles. Some patients, however, exhibited a different pattern of lncRNAs expression, low expression in plasma with high levels in ESCC tissues. At present, it was difficult to explain such phenomena; one possible hypothesis for that phenomenon could be the heterogeneity of primary tumor. At present, the exact biological roles of circulating lncRNAs in cancer patients remain unclear. Are they merely molecular remnants of necrotic tumor cells or do they play important roles in cell-to-cell communication? Obviously, more investigations will be needed to solve the exciting questions.

\section{Limitation of the study}

However, research limitations exist in our study, such as modest sample size, relatively low sensitivity qPCR method and failure in deep functional investigation. Further studies focused on the biological role of plasma lncRNAs are needed.

\section{Conclusions}

In summary, our results suggested that increased plasma lncRNA POU $3 F 3$ can be used as ideal tumor biomarker for ESCC detection, and that combination of POU3F3 and SCCA has a higher positive diagnostic rate of ESCC than POU3F3 or SCCA alone, in particular at its early stage.

\section{Material and methods}

\section{Ethical approval}

Written informed consent was obtained from each participant prior to blood and tumor samples collection. All of the clinical samples were obtained from Nanjing Medical University Nanjing First Hospital (Nanjing, China) and Huai'an First Hospital (Huai'an, China). The study protocol was approved by the Clinical Research Ethics Committee of Nanjing First Hospital and Huai'an First Hospital, respectively.

\section{Clinical samples and plasma preparation}

In this study, 147 consecutive hospitalized patients who had newly diagnosed with ESCC were selected from Nanjing Medical University affiliated Nanjing Hospital ( $\mathrm{n}=53$ ) and Nanjing Medical University affiliated Huai'an First Hospital $(n=94)$ between January 2013 and May 2014. All patients selected met the following inclusion criteria: pathological examination confirmed primary ESCC by available biopsy samples; and no anticancer treatments were given before surgery. Summarized in Additional file 8: Table S4 were the clinicopathological characteristics of the 147 patients, including gender, age, tumor size, CEA, SCCA, histologic grade, smoking status, alcohol consumption, TNM stage and clinical stage. The tumors were staged according to the 7th edition of 
tumor-node-metastasis (TNM) classification for esophageal carcinoma (UICC, 2009) [43].

One hundred and twenty-three adult healthy volunteer donors were enrolled as a normal control group. None of the donors have any esophageal disease or any other types of malignancy, with information detailed in Additional file 8: Table S4.

Fresh tumor tissues and paired adjacent normal tissues were obtained from ESCC patients and were immediately frozen in liquid nitrogen and then stored at $-80^{\circ} \mathrm{C}$ until RNA extraction.

Peripheral blood from ESCC patients was drawn before and $14 \mathrm{~d}$ after surgery. Up to $5 \mathrm{ml}$ of blood was collected from each subject in a $K_{2}$ EDTA plasma tube and was processed within $1 \mathrm{~h}$ for plasma collection. For serum collection, all blood samples were allowed to clot at room temperature for a minimum of $30 \mathrm{~min}$ and a maximum of $2 \mathrm{~h}$. Cell and cellular components-free plasma or serum was isolated from all blood samples using a two-step centrifugation protocol (2000 g for $10 \mathrm{~min}$ at $4^{\circ} \mathrm{C}, 12000 \mathrm{~g}$ for $10 \mathrm{~min}$ at $4^{\circ} \mathrm{C}$ ) to thoroughly remove cellular nucleic acids. After separation, plasma and serum samples were transferred to RNase DNasefree tubes and stored at $-80^{\circ} \mathrm{C}$ until total RNA extraction. Blood samples with hemolysis were excluded.

\section{Cell culture}

All cells were a generous gift from Dr. Zhi-Hua Liu, the State Key Laboratory of Molecular Oncology, Cancer Institute, Chinese Academy of Medical Sciences (Beijing, China). Human KYSE30, KYSE70, KYSE450, Eca 109 and HET-1A were cultured in RPMI medium 1640 (Invitrogen, Carlsbad, CA) containing 10\% fetal bovine serum (Gibco, Grand Island, NY) and 1\% penicillin-streptomycin at $37^{\circ} \mathrm{C}$ in $5 \% \mathrm{CO}_{2}$. Cells were plated in 6-well plate at a density of $2 \times 10^{5}$ per well, and then the medium was switched to fresh RPMI-1640 $12 \mathrm{~h}$ after plating. After incubation for 3 days, the cells and the cell culture media were separately collected for RNA isolation. The processing of conditioned media was the same as that described for plasma collection.

\section{Xenograft experiments}

The animal study was performed in accordance with the $\mathrm{NIH}$ animal use guidelines to explore the source of circulating lncRNAs. In brief, KYSE30 cells were collected at exponential growing stage when they reached $~ 70 \%$ confluence. About $1 \times 10^{6}$ cells in $50 \%$ matrigel were injected subcutaneously into the flanks of the BALB/C nude mice $(n=12)$. An equal number of mice were injected with $100 \mu \mathrm{l}$ of $50 \%$ matrigel in PBS as controls. Four weeks after implantation, mice were anesthetized and their blood was collected in EDTA tube using cardiac puncture and processed for isolation of plasma.

\section{RNA isolation}

RNA extraction from tissues and cultured cells was performed using Trizol reagent (Invitrogen, Carlsbad, CA, USA), whereas total RNA in plasma or cell culture media was isolated by using mirVana PARIS Kit (Ambion 1556, USA). Detailed description of RNA extraction was provided in Supporting Information (Additional file 9: Table S5).

\section{Quantitative real-time PCR (qPCR)}

An aliquot of $1 \mu \mathrm{g}$ total RNA was reverse transcribed into cDNA using PrimeScript ${ }^{\text {tw }}$ RT reagent Kit with gDNA Eraser (Takara: RR047A). The qPCR was then carried out using SYBR $^{\circ}$ Premix Ex Tag ${ }^{\text {mi }}$ II (Takara: RR820A) in $20 \mu \mathrm{l}$ reactions. All qRT-PCR reactions were performed on ABI 7500 Real-Time PCR System (Applied Biosystems, USA). Each sample was analyzed in triplicate and the specificity of each PCR reaction was confirmed by melt curve analyses. The compliance of the qPCR experiments with the MIQE (Minimum Information for Publication of Quantitative Real-Time PCR Experiments) guidelines was shown in the MIQE checklist [44] (Additional file 9: Table S5). All the qPCR target information were listed in Additional file 10: Table S7.

Four house-keeper genes (GAPGH, TBP, $\beta$-actin and HPRT1), which have been previously reported to be stably expressed in different human tissues or were once used in ESCC qPCR study, were chosen as candidate endogenous controls for the analysis of tissues and cells IncRNA. RefFinder, a web-based comprehensive tool (www.leonxie.com/referencegene.php), was then utilized to evaluate and screen the optimal reference gene.

The expression levels of lncRNAs were calculated using $\Delta \mathrm{Ct}$ method, where $\Delta \mathrm{Ct}=\mathrm{Ct}_{\text {target }}-\mathrm{Ct}_{\text {reference }}$, smaller $\Delta \mathrm{Ct}$ value indicates higher expression. Relative expression of $\operatorname{lncRNAs}$ was calculated using $2^{-\Delta \mathrm{Ct}}$ method normalized to endogenous control, with $\Delta \mathrm{Ct}=\mathrm{Ct}_{\text {target }}-$ $\mathrm{Ct}_{\text {reference, }}, \Delta \Delta \mathrm{Ct}=-($ sample $\Delta \mathrm{Ct}-$ control $\Delta \mathrm{Ct})$.

All the primers used in the present study were listed in the supporting information (Additional file 11: Table S6).

\section{Sequencing of qPCR products}

After gel extraction and purification, the qPCR products were then cloned into the $\mathrm{pUCm}-\mathrm{T}$ vector following the manufacturer's protocol (Sangon Biotech, Shanghai, China), and then sequencing was performed by the Sangon Biotech Co., Ltd.

\section{Additional files}

Additional file 1: Table S1. Raw Ct values of 21 pairs of ESCC tumor tissues and adjacent normal tissues. 
Additional file 2: Table S2. Correlation between GAPDH level (raw $C t$ value) in human plasma and clinicopathological factors of normal controls and ESCC patients.

Additional file 3: Text S1. Supplementary data.

Additional file 4: Figure S1. Sequencing Results of Plasma $\mathrm{qPCR}$ Products of POUBF3 (A), HNFIA-AST (B) and SPRY4-IT1 (C).

Additional file 5: Figure S2. Comparison plasma level of ENST00000435885 and AFAP1-AS1 between ESCC and normal control groups. ENST00000435885 (A) and AFAP1-AS1 (B) expression showed no significant differences between ESCC and normal controls. Data presented as $\triangle \mathrm{Ct}$ values normalized to GAPDH.

Additional file 6: Figure S3. Effect of delayed processing of blood on ESCC-related IncRNAs expression. $\bullet$, unfiltered plasma incubated at $4^{\circ} \mathrm{C}, \Delta$, filtered plasma incubated at room temperature. The symbols represented the means at specified time points.

Additional file 7: Table S3. Correlation between ESCC-related IncRNAs expression $(\Delta \mathrm{Ct})$ in plasma and clinicopathological characteristics of 143 ESCC patients.

Additional file 8: Table S4. Clinical characteristics of study population.

Additional file 9: Table S5. Checklist MIQE.

Additional file 10: Table S7. $\mathrm{QPCR}$ target information.

Additional file 11: Table S6. Primers sequences.

\section{Abbreviations}

IncRNA: Long non-coding RNA; ESCC: Esophageal squamous cell carcinoma; ROC: Receiver operating characteristic curve; AUC: Area under the ROC curve; SCCA: Squamous cell carcinoma antigen; CEA: Carcinoembryonic antigen; CA 19-9: Carbohydrate antigen (CA) 19-9; TNM: Tumor-node-metastasis; q-PCR: Quantitative real-time polymerase chain reaction; Cl: Confidence interval.

\section{Competing interests}

The authors declare that they have no conflict of interests.

\section{Authors' contributions}

X.C. and Y.T. conception and design, collection and/or assembly of data, data analysis and interpretation, manuscript writing, final approval of manuscript, X.Z. conception and design, collection and/or assembly of data, data analysis and interpretation, manuscript writing; X.W., Z.L., T.Y., and W.S. data analysis and interpretation; J.L., H.X. and Q.W. provision of study materials. All authors read and approved the final manuscript.

\section{Authors' information}

Yu-suo Tong, Xiao-Wei Wang and Xi-lei Zhou considered as joint first authors.

\section{Acknowledgements}

We would like to thank all of the study participants for agreeing to participate in medical research. This work was supported by National Nature Science Foundation of China (Grant No.H1617/81372656) and Science and Technology Project on Clinical Medicine of Jiangsu Province (Grant No. BL2014011), and the Graduate Research and Innovation Projects of Jiangsu Province (Grant No. CXLX_0567).

\section{Author details}

'Department of Surgical Oncology, Nanjing Frist Hospital, Nanjing Medical University, Nanjing, Jiangsu, China. ${ }^{2}$ Department of Medical Oncology, Huai'an First People's Hospital Affiliated to Nanjing Medical University, Huai'an, Jiangsu, China. ${ }^{3}$ Department of Radiation Oncology, Huai'an First People's Hospital Affiliated to Nanjing Medical University, Huai'an, Jiangsu, China. ${ }^{4}$ Department of Thoracic Surgery, Huai'an First People's Hospital Affiliated to Nanjing Medical University, Huai'an, Jiangsu, China.

Received: 22 August 2014 Accepted: 9 December 2014 Published: 21 January 2015

\section{References}

1. van Hagen P, Hulshof MC, van Lanschot JJ, Steyerberg EW, van Berge Henegouwen MI, Wijnhoven BP, et al. Preoperative chemoradiotherapy for esophageal or junctional cancer. N Engl J Med. 2012;366:2074-84.

2. Sakai NS, Samia-Aly E, Barbera M, Fitzgerald RC. A review of the current understanding and clinical utility of miRNAs in esophageal cancer. Semin Cancer Biol. 2013;23:512-21.

3. Hirajima S, Komatsu S, Ichikawa D, Takeshita $H$, Konishi H, Shiozaki A, et al. Clinical impact of circulating miR-18a in plasma of patients with oesophageal squamous cell carcinoma. Br J Cancer. 2013;108:1822-9.

4. Kosugi S, Nishimaki T, Kanda T, Nakagawa S, Ohashi M, Hatakeyama K. Clinical significance of serum carcinoembryonic antigen, carbohydrate antigen 19-9, and squamous cell carcinoma antigen levels in esophageal cancer patients. World J Surg. 2004;28:680-5.

5. Qi P, Du X. The long non-coding RNAs, a new cancer diagnostic and therapeutic gold mine. Mod Pathol. 2012;26:155-65.

6. Ren S, Wang F, Shen J, Sun Y, Xu W, Lu J, et al. Long non-coding RNA metastasis associated in lung adenocarcinoma transcript 1 derived miniRNA as a novel plasma-based biomarker for diagnosing prostate cancer. Eur J Cancer. 2013:49:2949-59.

7. Li X, Wu Z, Mei Q, Guo M, Fu X, Han W. Long non-coding RNA HOTAIR, a driver of malignancy, predicts negative prognosis and exhibits oncogenic activity in oesophageal squamous cell carcinoma. Br J Cancer. 2013;109:2266-78.

8. Redis RS, Sieuwerts AM, Look MP, Tudoran O, Ivan C, Spizzo R, et al. CCAT2, a novel long non-coding RNA in breast cancer expression study and clinical correlations. Oncotarget. 2013:4:1748-62.

9. Gutschner T, Hämmerle M, Eissmann M, Hsu J, Kim Y, Hung G, et al. The noncoding RNA MALAT1 is a critical regulator of the metastasis phenotype of lung cancer cells. Cancer Res. 2013;73:1180-9.

10. Yuan S-X, Yang F, Yang Y, Tao Q-F, Zhang J, Huang G, et al. Long noncoding RNA associated with microvascular invasion in hepatocellular carcinoma promotes angiogenesis and serves as a predictor for hepatocellular carcinoma patients' poor recurrence-free survival after hepatectomy. Hepatology. 2012;56:2231-41.

11. Liu Q, Huang J, Zhou N, Zhang Z, Zhang A, Lu Z, et al. LncRNA loc285194 is a p53-regulated tumor suppressor. Nucleic Acids Res. 2013;41:4976-87.

12. Tsui NB, Ng EK, Lo YM. Stability of endogenous and added RNA in blood specimens, serum, and plasma. Clin Chem. 2002;48:1647-53.

13. Zanutto S, Pizzamiglio S, Ghilotti M, Bertan C, Ravagnani F, Perrone F, et al. Circulating miR-378 in plasma: a reliable, haemolysis-independent biomarker for colorectal cancer. Br J Cancer. 2014;110:1001-7.

14. Zhang J, Zhao H, Gao Y, Zhang W. Secretory miRNAs as novel cancer biomarkers. Biochimica et Biophysica Acta (BBA) - Reviews on Cancer. 2012;1826:32-43.

15. Shao $Y$, Ye M, Jiang $X$, Sun W, Ding $X$, Liu Z, et al. Gastric juice long noncoding RNA used as a tumor marker for screening gastric cancer. Cancer. 2014.

16. Chen F-J, Sun M, Li S-Q, Wu Q-Q, Ji L, Liu Z-L, et al. Upregulation of the long non-coding rna hotair promotes esophageal squamous cell carcinoma metastasis and poor prognosis. Mol Carcinog. 2013;52:908-15.

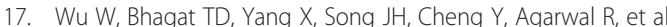
Hypomethylation of noncoding DNA regions and overexpression of the long noncoding RNA, AFAP1-AS1, in Barrett's esophagus and esophageal adenocarcinoma. Gastroenterology. 2013;144:956-66. e954.

18. Li W, Zheng J, Deng J, You Y, Wu H, Li N, et al. Increased levels of the long intergenic non-protein coding RNA POU3F3 promote DNA methylation in esophageal squamous cell carcinoma cells. Gastroenterology. 2014:146:1714-26. e1715

19. Yang $X$, Song $J H$, Cheng $Y, W u W$, Bhagat $T, Y u Y$, et al. Long non-coding RNA HNF1A-AS1 regulates proliferation and migration in oesophageal adenocarcinoma cells. Gut. 2014;63:881-90.

20. Gao T, He B, Pan Y, Xu Y, Li R, Deng Q, et al. Long non-coding RNA 91H contributes to the occurrence and progression of esophageal squamous cell carcinoma by inhibiting IGF2 expression. Mol Carcinog. 2014.

21. Wang CM, Wu QQ, Li SQ, Chen FJ, Tuo L, Xie HW, et al. Upregulation of the long non-coding RNA PIncRNA-1 promotes esophageal squamous carcinoma cell proliferation and correlates with advanced clinical stage. Dig Dis Sci. 2014;59(8):591-7.

22. Xie HW, Wu QQ, Zhu B, Chen FJ, Ji L, Li SQ, et al. Long noncoding RNA SPRY4-IT1 is upregulated in esophageal squamous cell carcinoma and associated with poor prognosis. Tumour Biol. 2014;35(8):7743-54. 
23. Li J, Chen Z, Tian L, Zhou C, He MY, Gao Y, et al. LncRNA profile study reveals a three-IncRNA signature associated with the survival of patients with oesophageal squamous cell carcinoma. Gut. 2014;63(11):1700-10.

24. Andersen $\mathrm{CL}$, Jensen JL, Ørntoft TF. Normalization of real-time quantitative reverse transcription-PCR data a model-based variance estimation approach to identify genes suited for normalization, applied to bladder and colon cancer data sets. Cancer Res. 2004;64:5245-50.

25. Pritchard CC, Kroh E, Wood B, Arroyo JD, Dougherty KJ, Miyaji MM, et al. Blood Cell Origin of Circulating MicroRNAs: A Cautionary Note for Cancer Biomarker Studies. Cancer Prevent Res. 2011;5:492-7.

26. Schwarzenbach H, Hoon DS, Pantel K. Cell-free nucleic acids as biomarkers in cancer patients. Nat Rev Cancer. 2011;11:426-37.

27. Lukaszewicz-Zajac M, Mroczko B, Kozlowski M, Niklinski J, Laudanski J, Szmitkowski M. Higher importance of interleukin 6 than classic tumor markers (carcinoembryonic antigen and squamous cell cancer antigen) in the diagnosis of esophageal cancer patients. Dis Esophagus. 2012;25:242-9.

28. Zheng X, Xing S, Liu XM, Liu W, Liu D, Chi PD, et al. Establishment of using serum YKL-40 and SCCA in combination for the diagnosis of patients with esophageal squamous cell carcinoma. BMC Cancer. 2014;14:490-500.

29. Zhou JH, Zhang B, Kernstine KH, Zhong L. Autoantibodies against MMP-7 as a novel diagnostic biomarker in esophageal squamous cell carcinoma. World J Gastroenterol. 2011;17:1373-8.

30. Takeshita N, Hoshino I, Mori M, Akutsu Y, Hanari N, Yoneyama Y, et al. Serum microRNA expression profile: miR-1246 as a novel diagnostic and prognostic biomarker for oesophageal squamous cell carcinoma. $\mathrm{Br} J$ Cancer. 2013;108:644-52.

31. Yamamoto K, Oka M, Hayashi H, Tangoku A, Gondo T, Suzuki T. CYFRA 21-1 is a useful marker for esophageal squamous cell carcinoma. Cancer. 1997;79:1647-55

32. Łukaszewicz-Zajac M, Mroczko B, Kozłowski M, Nikliński J, Laudański J, Szmitkowski M. Elevated levels of serum metalloproteinase 9 in patients with esophageal squamous cell carcinoma. Pol Arch Med Wewn. 2009;119:558-63.

33. Lardizabal MN, Nocito AL, Daniele SM, Ornella LA, Palatnik JF, Veggi LM. Reference genes for real-time PCR quantification of microRNAs and messenger RNAs in rat models of hepatotoxicity. PLoS One. 2012;7:e36323.

34. Sauer E, Babion I, Madea B, Courts C. An evidence based strategy for normalization of quantitative PCR data from miRNA expression analysis in forensic organ tissue identification. Forensic Sci Int Genet. 2014;13:217-23.

35. Jacob F, Guertler R, Naim S, Nixdorf S, Fedier A, Hacker NF, et al. Careful selection of reference genes is required for reliable performance of RT-QPCR in human normal and cancer cell lines. PLoS One. 2013;8:e59180.

36. Ng EK, Tsui NB, Lam NY, Chiu RW, Yu SC, Wong SC, et al. Presence of Filterable and Nonfilterable mRNA in the Plasma of Cancer Patients and Healthy Individuals. Clin Chem. 2002;48:1212-7.

37. Wittmann J, Jäck H-M. Serum microRNAs as powerful cancer biomarkers. Biochimica et Biophysica Acta (BBA) - Reviews on Cancer. 2010;1806:200-7.

38. Redova M, Sana J, Slaby O. Circulating miRNAs as new blood-based biomarkers for solid cancers. Future Oncol. 2013;9:387-402.

39. Reis EM, Verjovski-Almeida S. Perspectives of Long Non-Coding RNAs in Cancer Diagnostics. Frontiers Genet. 2012;3:1-8.

40. Chen G, Wang J, Cui Q. Could circulating miRNAs contribute to cancer therapy. Trends Mol Med. 2013;19:71-3.

41. Liu J, Gao J, Du Y, Li Z, Ren Y, Gu J, et al. Combination of plasma microRNAs with serum CA19-9 for early detection of pancreatic cancer. Int J Cancer. 2012;131:683-91.

42. Kumarswamy R, Bauters C, Volkmann I, Maury F, Fetisch J, Holzmann A, et al. Circulating long noncoding RNA, LIPCAR, predicts survival in patients with heart failure. Circ Res. 2014;114:1569-75.

43. Sobin LH, Gospodarowicz MK, Wittekind C. TNM classification of malignant tumours, 7th edition. 2010.

44. Bustin SA, Benes V, Garson JA, Hellemans J, Huggett J, Kubista M, et al. The MIQE guidelines: minimum information for publication of quantitative real-time PCR experiments. Clin Chem. 2009:55:611-22.

doi:10.1186/1476-4598-14-3

Cite this article as: Tong et al:: Identification of the long non-coding RNA POU3F3 in plasma as a novel biomarker for diagnosis of esophageal squamous cell carcinoma. Molecular Cancer 2015 14:3.

\section{Submit your next manuscript to BioMed Central and take full advantage of:}

- Convenient online submission

- Thorough peer review

- No space constraints or color figure charges

- Immediate publication on acceptance

- Inclusion in PubMed, CAS, Scopus and Google Scholar

- Research which is freely available for redistribution

Submit your manuscript at www.biomedcentral.com/submit 